УДК 1:3

Е.А. Тюгашев

Новосибирск

\title{
СТАНОВЛЕНИЕ СОЦИОЛОГИИ ФИЛОСОФИИ: Е.В. ДЕ РОБЕРТИ - П.А. СОРОКИН
}

Цитирование: Тюгашев Е.А. Становление социологии философии: Е.В. Де Роберти - П.А. Сорокин // Наследие. 2020, № 2(17). - С.55-70.

DOI: https://doi.org/10.31119/hrtg.2020.2.4

Citation: Tyugashev E.A. Stanovlenie sociologii filosofii: E.V. de Roberti P.A. Sorokin [Formation of the sociology of philosophy: E.V. de Roberti - P.A. Sorokin] // Nasledie [Heritage]. 2020, No. 2 (17). - pp.55-70.

DOI: https://doi.org/10.31119/hrtg.2020.2.4

П.А. Сорокин был не только учеником, но и идейным последователем E.В. Де Роберти. «Социальная и культурная динамика» является исследованием в области сочиологии философии, развивающим основные положения общей сочиологии Е.В. Де Роберти и его работы «Прочедшее философии. Опьт сочиологического исследования общих законов развития философской мысли». С учетом данных работ научная традиция сочиологии философии может быть представлена эстафетой: Платон - О. Конт - Е.В. Де Роберти П.А. Сорокин - Р. Коллинз.

Ключевые слова: сочиология культуры, сочиология философии, П.А. Сорокин, Е.В. Де Роберти, Р. Коллинз, парадигма.

Tyugashev E.A. Formation of the sociology of philosophy: E.V. de Roberti P.A. Sorokin

P.A. Sorokin was not only a student, but also a scientific follower of E.V. de Roberti. "Social and cultural dynamics» is a study in the field of the sociology of philosophy, developing the main provisions of the general sociology of E. $V$. de Roberti and his work "Philosophical past. Experience of sociological research of general laws in development of philosophical thought». Taking into account these works the scientific tradition of the sociology of philosophy can be represented by the relay: Plato Au. Comte-E.V. de Roberti-P.A. Sorokin-R. Collins.

Key words: sociology of culture, sociology of philosophy, P. A. Sorokin, E. V. de Roberti, R. Collins, paradigm.

\section{Проблема начала социологии философии}

В корпусе частных социологических наук социология философии малозаметна, в отличие от развитых и дифференцированных социологий искусства, науки и рели- 
гии. Данное положение принято объяснять ее недавним возникновением, связываемым с публикацией фундаментального труда Р. Коллинза «Социология философий: глобальная теория интеллектуального изменения» [Collins, 1998]. Так, В.И. Красиков называет Р. Коллинза «первопроходцем» в социологическом исследовании философии [Красиков, 2010, с.5]. Н.В. Попкова пишет о том, что контуры социологии философии были намечены только 20 лет назад [Попкова, 2019, с.136]. А по оценке Н.С. Розова, Р. Коллинз выстроил новую дисциплину, дочернюю по отношению к социологии науки [Розов, 2016, с.292].

Думается, эти оценки достоверны, если относить их к признанию научным сообществом выделения социологии философии как отдельной дисциплинарной области в комплексе социологических наук. В этом плане исследование Р. Коллинза воспринято как парадигмальное, конституирующее социологию философии как «нормальную» науку.

Формирование любой парадигмы обычно осуществляется не сразу, а после серии более или менее удачных попыток выдвижения «кандидатов в парадигму» [Кун, 2003 , с.202]. Аналогично можно предполагать, что социология философии возникла ранее, чем ее признало научное сообщество. Поэтому представляется необходимым восстановить звенья научной традиции.

\section{Угроза провинциалистской перспективы в социологии философии}

В связи с восприятием Р. Коллинза как первопроходца в области социологии философии мне кажется актуальным замечание Н.С. Розова: «Не успев освоить один пласт идей, связать его с традицией, поставить и решить соответствующие проблемы, наша интеллектуальная публика перескакивает на новую свежедоставленную моду, углубляя тем самым колею провинциализма» [Розов, 2016, с.324].

Угроза такой провинциалистской перспективы весьма велика не только для российских гуманитариев. Например, Р. Коллинз избегает историографического обзора в области предмета своего исследования, упоминая только о существовании социологии знания и социологии науки как ближайших родственников в социологии идей [Коллинз, 2002, с.57]. Поступая так, он, в общем-то, следует одному из своих резюмирующих выводов, согласно которому движение фронта философских исследований происходит путем оперативного переключения (или «перескакивания»по Н.С. Розову?) на новую тематику. Поскольку в науке «быстрых открытий» освоение имеющего наследия задерживает «снятие сливок», научная традиция, работы предшественников подвергаются забвению «во имя славы немногих» [Коллинз, 2002, с.988].

Правда, слава может оказаться сомнительной. Как констатирует Н.С. Розов, историки философии отметили вторичность подхода Р. Коллинза и недостаточное знание конкретного материала [Розов, 2016, с.295]. Другими словами, ничего нового из его работы, ранее им неизвестного, они не узнали. Например, «сетевые карты» и раньше использовались для схематизации историко-философского материала [Диоген Лаэртский, 1986, с.506]. 
Н.С. Розов полагает важным выделение Коллинзом такого феномена, как пространство интеллектуального внимания [Розов, 2016, с.296]. В отношении данного результата заметим следующее. Во-первых, это социально-психологический феномен, не представляющий поэтому профессионального интереса для социологов. Во-вторых, это характеристика любого вида духовной деятельности (научной, художественной, религиозной и т. п.), а не собственно философской деятельности. По-видимому, не случайно Н.С. Розов о читательской аудитории говорит как об интеллектуальной публике, а не как о профессионалах в конкретных дисциплинарных областях. Объяснимо тогда, что по эпистемологическому статусу «глобальная теория интеллектуального изменения» Р. Коллинза воспринимается как относящаяся к научно-популярной литературе.

Если же избавляться от провинциализма и всерьез наращивать культурный капитал, как принципиально настаивает Н.С. Розов, то необходимо не просто «соотнесение с уже известными работами, сопоставимыми по тематике и широте охвата» [Розов, 2016, с.309], а тщательное освоение научного наследия в данной дисциплинарной области. Н.С. Розов честно признается, что такие работы - за исключением классических «историй» философий - сопоставимого уровня ему неизвестны [Розов, 2016, с.309]. Думается, такие работы, написанные авторами, в свое время не менее авторитетными, чем Р. Коллинз, все же есть.

\section{«Кандидаты в парадигму»}

Внешнему признанию социологии философии, очевидно, предшествовал этап отсутствия такого признания. На этом этапе социология философии была выделена, манифестирована как самостоятельная область исследований. Примером такой манифестации является фундаментальная монография Е.В. Де Роберти «Прошедшее философии. Опыт социологического исследования общих законов развития философской мысли» [Роберти, 1887]. Как известно, она была запрещена в России и вторично опубликована во Франции под названием «Старая и новая философия» [Roberti, 1887]. Ребрендинг исследования, перепозиционирование его как относящего к области истории философии приостановили формирование социологии философии.

Представляет интерес, что Е.В. Де Роберти указал на еще одного, более раннего «кандидата в парадигму»: «На философскую систему так мало еще привыкли смотреть, как на факт социологического порядка, что Огюст Конт едва ли не был до сих пор единственным мыслителем, систематически пытавшимся приложить методы общественных наук к изучению этого разряда явлений» [Роберти, 1887, с.309]. Заслугу родоначальника социологии Е.В. Де Роберти видел в открытии «закона трех состояний», описывающего место и роль философии в социальной динамике.

Излагая социологическое учение О. Конта, Ю.Н. Давыдов подчеркнул, что на метафизической стадии философия выступает как основной фактор общественного развития [История теоретической социологии..., 2020, с.68]. Высокая оценка социальной функции философов отсылает еще к одному более раннему источнику социологии философии. 
Напомню, что социальное учение Платона вполне обоснованно интерпретировалось не только как социальная утопия, но и как дескриптивная социология [Поппер, 1992, с.67-122]. На мой взгляд, можно говорить и о нормативной социологии Платона, а в ней философы занимают заметное место. Поэтому «Государство» Платона первоисточник по социологии философии, особенно если учесть, что в нем нашла отражение триадичная социальная структура индоевропейского социума с верховенством жрецов, фактически являвшихся философами, как показали позднейшие интерпретации [Возчиков, 2014].

Таким образом, восстанавливается заслуживающая внимания традиция становления социологии философии: Платон - О. Конт - Е.В. Де Роберти - .. - Р. Коллинз. Она представляется довольно связной, по крайней мере, в аспекте идейной преемственности. Но в этой традиции имеется недостающее звено, т. к. никакой связи между Е.В. Де Роберти и Р. Коллинзом не прослеживается.

\section{Недостающее звено - «ужасный Питирим Сорокин!»}

Одним из важных результатов своего исследования Р. Коллинз считает открытие закона малых чисел - границ диапазона (от 3 до 6) интеллектуальных позиций, находящихся в фокусе общественного внимания. В комментариях к этому закону почему-то не указывается, что термин «закон малых чисел» дублирует термин, ранее использованный в когнитивной психологии для обозначения ошибки эвристики преувеличенной веры в надежность выводов, сделанных по результатам малой выборки [Tversky, Kahneman, 1971].

Закон малых чисел был сформулирован в противоположность известному из теории вероятности закону больших чисел, который, наоборот, утверждает, что при неограниченном количестве испытаний усредненные результаты стремятся к константе. Сопоставление этих законов [Орлова, 2019], безотносительно к конкретному их содержанию, наводит на мысль, что открытию Р. Коллинза могло предшествовать исследование в области социологии философии, оперировавшее «большими числами», т. е. довольно значительными статистическими рядами.

На это предположение также косвенно ориентирует следующее замечание С. Фуллера: «Коллинзовская перспектива не дает нам увидеть, как люди вне академии, будь то профессиональные писатели, журналисты, юристы, предприниматели, священники или идеологи, могли вообще становиться главными силами интеллектуального изменения - разве что если некая пуповина по-прежнему связывала их с местами прежнего обучения» [Фуллер, 2018, с.119]. Действительно, коллинзовская перспектива сфокусирована на переднем крае фронта исследований, где он выделяет от 3 до 6 авангардных, идущих на прорыв групп, но оставляет в стороне остальную часть фронта - взаимодействующие виды и роды «вооруженных» сил, обеспечивающие тыл.

Следовательно, возможна другая перспектива, которая в противоположность подходу Р. Коллинза:

- во-первых, работает с «большими числами»; 
- во-вторых, учитывает взаимодействующие с философией виды интеллектуальной деятельности;

- в-третьих, не упускает из виду обеспечивающий тыл, т. е. духовную культуру эпохи в целом, представленную в ментальности масс.

Не требуется большой эрудиции, чтобы указать на работу, в которой данная перспектива была реализована. Это работа П.А. Сорокина «Социальная и культурная динамика: Исследование изменений в больших системах искусства, истины, этики, права и общественных отношений» [Sorokin, 1957].

Мы находим в ней длинные статистические ряды, охватывающие период в 2,5 тысячи лет. Динамика философии («системы истины») рассматривается сопряженно с развитием других видов духовной деятельности, а также с изменениями в общественной практике. Не упускается из виду ментальность масс, представленная преимущественно идеациональной, чувственной и идеалистической культурами.

И поразительно то, что П.А. Сорокин фактически оперирует «законом малых чисел», т. е. выделяет от 3 до 6 значимых интеллектуальных позиций. В отличие от подхода Р. Коллинза, П.А. Сорокин не персонализирует эти позиции и рассматривает их как сквозные для всего историко-философского процесса в целом.

Р. Коллинз не упоминает П.А. Сорокина в своей «Социологии философий», но с его «Социальной и культурной динамикой», по-видимому, хотя бы в общих чертах был знаком. Во время обучения в Гарвардском университете Р. Коллинз не встречался с П.А. Сорокиным, но был наслышан о нем. «Когда он с кем-то встречался, он мог сказать: “Я ужасный Питирим Сорокин!”》 - вспоминает Р. Коллинз [Интервью с профессором..., 2004, с.18].

Таким образом, в качестве недостающего звена в традиции становления социологии философии можно рассматривать П.А. Сорокина. Р. Коллинз не вступал в непосредственный контакт с ним. Но в сети научных коммуникаций между фигурантами возможны опосредованные и нейтральные контакты, передающие культурный капитал [Красиков, 2010, с.12]. Не исключено, что случай П.А. Сорокина и Р. Коллинза относится именно к такой категории контактов. В случае же Е.В. Де Роберти и П.А. Сорокина мы наблюдаем комплекс связующих отношений.

\section{Е.В. Де Роберти - П.А. Сорокин: линии преемственности}

Важным направлением исследования жизни П.А. Сорокина стало восстановление полной картины его коммуникаций в кругу петербургских и московских интеллектуалов, занимавшихся вопросами философии, социологии, истории и права. Рассматриваются духовное влияние на П.А. Сорокина со стороны П.Л. Лаврова [Золотарев, 2014a], многоплановые отношения с Н.И. Кареевым [Золотарев, 2013] и М.М. Ковалевским [Золотарев, 2014б], взаимодействие с Б.А. Кистяковским [Бочкарева, 2017]. Авторы этих и других публикаций пока не ориентируются на сетевой анализ Р. Коллинза, но такая методологическая возможность является открытой.

В сети научных коммуникаций Е.В. Де Роберти и П.А. Сорокин были связаны, прежде всего, как учитель и ученик. На протяжении всей своей жизни П.А. Сорокин 
относил Е.В. Де Роберти к группе своих великих учителей наряду с Л.И. Петражицким и М.М. Ковалевским [Сапов, 2019, с.186-187].

Кроме того, с 1910 г. П.А. Сорокин вел занятия на возглавлявшейся Е.В. Де Роберти кафедре социологии Психоневрологического института [Буланова, 2019a, с.15], а после смерти того стал его преемником в преподавании курса социологии [Буланова, 2019б, с.96]. Составленную Е.В. Де Роберти программу курса социологии П.А. Сорокин считал одной из лучших в России [Буланова, 2019б, с.94]. П.А. Сорокин публиковался в серийном сборнике «Новые идеи в социологии», издававшемся под редакцией Е.В. Де Роберти. Таким образом, налицо принадлежность к одной организационной структуре и академическая преемственность.

Немаловажной была институциональная поддержка. Е.В. Де Роберти относился к тем, кто оказывал политическое покровительство молодому П.А. Сорокину [Сапов, 2019, с.187]. Благодаря этому П.А. Сорокин стал масоном и впоследствии - секретарем А.Ф. Керенского.

В целом П.А. Сорокин относил Е.В. Де Роберти к социологам «первого разряда», чьи работы составили один из этапов развития социологии [Сорокин, 2019, с.191]. В обзорных исследованиях П.А. Сорокина по истории социологии Е.В. Де Роберти упоминался в ряду ведущих социологов [Голосенко, 2001, с.106].

Таким образом, П.А. Сорокин был тесно связан с Е.В. Де Роберти и рассматривал его научное наследие как образец, пример для подражания, высоко оценивая его. Это отношение должно было выразиться не только в чисто организационной связи, но и в интеллектуальном влиянии Е.В. Де Роберти на П.А. Сорокина.

На данный канал научной коммуникации уже обращалось внимание. В частности, подчеркивалось, что обращение к трудам Е.В. Де Роберти весьма информативно для понимания взглядов П.А. Сорокина [Медушевский, 2013, с.108]. Высказывалось мнение о том, что П.А. Сорокин унаследовал от Е.В. Де Роберти навык методологическое сомнения, установку на пересмотр пути развития социологии [Сапов, 2019, c. 188].

Сам же П.А. Сорокин в качестве ключевых идей Е.В. Де Роберти рассматривал:

- трактовку объекта социологии как человеческого взаимодействия, основанного на культуре [Сорокин, 2019, с.192];

- интерпретацию культуры как результата конденсации психики в различных формах общественной мысли [Сорокин, 2019, с.192].

Примечательно, что уже в этой ранней статье, подготовленной в 1915 г., П.А. Сорокин выделял следующие основные формы культуры: науку, религию, философию, искусство и - практику, регулируемую правом и нравственностью. В данной структурации он усматривал один из центральных пунктов неопозитивизма Е.В. Де Роберти.

Как можно заметить, все эти ключевые идеи были приняты П.А. Сорокиным и стали основой концептуального каркаса его будущих трудов. Правда, в «Социальной и культурной динамике» из всех форм культуры искусство как объект исследования переместилось на первый план.

Таким образом, можно предполагать, что связь Е.В. Де Роберти и П.А. Сорокина не была чисто формальной связью преподавателя и слушателя. Она была дополнена опытом сотрудничества и академической преемственностью в рамках научной 
школы, институциональной поддержкой в общественной жизни. Наряду с этим для П.А. Сорокина была значима идейная преемственность. Он признал ряд идей Е.В. Де Роберти концептуально значимыми и исходил из них в своем научном творчестве.

Указанная прямая идейная преемственность малозаметна в силу слабой изученности работ Е.В. Де Роберти. Поэтому обрисуем кратко интересующее нас его социологическое видение философии.

\section{Е.В. Де Роберти: абрис социологии философии}

В.П. Кошарный отметил, что Е.В. Де Роберти в труде «Прошедшее философии. Опыт социологического исследования общих законов развития философской мысли» использовал социологический подход как составную часть методологии историко-философской науки [Кошарный, 2013, с.43]. Действительно, Е.В. Де Роберти считал социологию единственно возможной наукой в изучении прошлого философии [Роберти, 1887, с.5]. Социологический аспект анализа выразился в том, что философия рассматривалась в качестве составной части культуры общества и в связи с его эволюцией [Кошарный, 2013, с.45]. Идею исследования истории философии с социологической точки зрения В.П. Кошарный считает весьма продуктивной.

По существу, первая часть работы Е.В. Де Роберти является историко-философским обзором эволюции материализма, идеализма и сенсуализма. Общую тенденцию эволюции философской мысли он видел в формировании научной философии и философии науки. В социологическом плане Е.В. Де Роберти приходит к двум основным выводам.

Во-первых, к выводу об исторической необходимости и «законности» философии как устойчивого стремления к обобщению знаний [Роберти, 1887, с.237].

Во-вторых, к пониманию содержания философии как результата взаимодействия накопленной суммы знаний и иных факторов цивилизации, каждый из которых мог оказаться главенствующим в зависимости от условий общественного развития [Роберти, 1887, с.240-242].

Таким образом, Е.В. Де Роберти предложил социологическое оправдание бытия философии, снял с нее вину за ее существование. В интерпретации содержания философии он занял экстерналистскую позицию.

По итогам анализа «прошедшего философии» Е.В. Де Роберти сформулировал несколько эмпирических законов ее развития.

Во-первых, это закон трех типов метафизики - устойчивой ее дифференциации на материализм, идеализм и сенсуализм [Роберти, 1887, с.255]. Указанные типы философии являются распространением метафизических гипотез на всевозможные явления.

Во-вторых, это закон соотношения между наукой и философией, согласно которому философия развивается благодаря обобщению данных различных наук, а последние не зависят от философии в своем развитии. «Между тем, один из главнейших результатов нашего исследования состоял именно в раскрытии истинного генезиса философских обобщений, в доказательстве, что последние первоначально 
всегда выносятся из наших специальных знаний и только тогда уже, в свою очередь, могут в более или менее сильной степени реагировать на них, - писал он. - Это одинаково справедливо относительно теологических, метафизических и научно-философских обобщений, все они в равной мере получают свою кровь и плоть от соответствующих частных понятий и затем уже, в таком организованном виде, вносятся обратно в пределы специального знания» [Роберти, 1887, с.291].

Поэтому состояние науки определяет состояние философии. А влияние последней на науки и общественное развитие преувеличено. Как следствие, не действует якобы «верховный» закон убывающей прогрессии философских концептов [Роберти, 1887, с.266], т. е. сжатия предмета философии вследствие передачи отдельных ее областей частным наукам.

В-третьих, это закон трех философских состояний (или закон последовательной смены трех фаз философского развития) - теологической философии, метафизической философии и научной философии. Данный закон уточняет, по мнению Е.В. Де Роберти, закон трех состояний О. Конта. Если последний относил его к развитию научных понятий, то Е.В. Де Роберти полагал, что научные понятия не являются теологическими или метафизическими понятиями, тогда как философские понятия в этих состояниях могут находиться [Роберти, 1887, с.270-271].

Таким образом, Е.В. Де Роберти развеял ряд устоявшихся стереотипов в отношении оценки положения философии в обществе. Кроме того, он легитимировал философию в рамках позитивизма, который, с одной стороны, отрицал положительную ценность философии, а с другой стороны - позиционировал себя как позитивную философию.

\section{П.А. Сорокин как социолог философии}

П.А. Сорокин свой главный труд «Социальная и культурная динамика» позиционировал как относящийся к социологии культуры [Сорокин, 2006, с.26]. В качестве особых феноменов культуры он выделял науку, философию, религию, искусство, технику. Поэтому в рамках его социологии культуры является логичной разработка социологии отдельных феноменов культуры.

В настоящее время обсуждаются результаты исследований П.А. Сорокина в области социологии религии [Муравьев, 2016; Смирнов, 2009; Яблоков, 2019] и социологии науки [Меняева, 2006; Сандстром, 2010]. Результаты исследований искусства рассматриваются в основном в историко-культурологическом ракурсе [Сухая, 2011; Тюгашев, 2019; Хренов, 2014a; Хренов, 2014б) и лишь изредка собственно в социологическом аспекте [Некрасов, Федосов, 2014]. Публикаций по социологии философии и социологии техники П.А. Сорокина нами не выявлено.

Итак, в качестве одной из форм культуры П.А. Сорокин рассматривал философию, которая в «Социальной и культурной динамике» стала объектом экспертного количественного и качественного анализа. Особое внимание было уделено статистическому описанию флуктуаций основных философских направлений: 
- в гносеологии: эмпиризма, рационализма, мистицизма, скептицизма, фидеизма, критицизма, реализма, концептуализма, номинализма;

- в онтологии: материализма, идеализма, этернализма, детерминизма и индетерминизма, причинности, атомизма, механицизма, витализма, циклизма и прогрессизма;

- в этике: эвдемонизма, гедонизма, утилитаризма, ригоризма, альтруизма.

Таким образом, социология философии охватила множество различных направлений.

Основные направления философии П.А. Сорокин рассматривал в аспекте принадлежности их к основным типам культуры - идеациональному, чувственному и идеалистическому. Ранее было показано, что эти типы культуры выделены в соответствии с конкретными типами ментальности, а последние дифференцированы по философским признакам [Тюгашев, 2015, с.97]. Как следствие, можно считать, что все формы культуры (религия, наука, искусство), а также все типы социальности рассматривались П.А. Сорокиным в философском аспекте [Попков, Тюгашев, 2018, c.60]. Поэтому «Социальная и культурная динамика» в целом может интерпретироваться как работа в области социологии философии.

Выделение философской ментальности как объекта исследования стало продолжением разработок в области социологии менталитета, инициированных Э. Дюркгеймом и поддержанных впоследствии Р. Мертоном [Тюгашев, Попков, 2018, с.16-17]. Благодаря этому научному достижению П.А. Сорокин смог осуществить масштабный социологический анализ философии в трех ипостасях ее существования - в виде профессиональной философии, на уровне менталитета культуры, а также в ее проявлениях в различных формах культуры (искусстве, науке, религии и т.д.).

Кроме выявления соотношений различных форм философского менталитета, пронизывающих все формы культуры, П.А. Сорокин выделил еще два аспекта социологического анализа философии: а) «сродство» типов философской ментальности с типами социальных отношений (семейственными, принудительными, договорными); б) взаимообусловленность типов философской ментальности и ментальностей социальных групп [Тюгашев, 2015, с.104].

Таким образом, «Социальная и культурная динамика» П.А. Сорокина является масштабным исследованием в области социологии философии. По сравнению с работой Е.В. Де Роберти, где философия рассматривалась исключительно как функция (следствие) цивилизации, в ней осуществлено существенное продвижение в понимании социальной роли философии как фактора (причины) общественного развития.

\section{Е.В. Де Роберти - П.А. Сорокин: идейная преемственность в области социологии философии}

П.А. Сорокин был хорошо знаком с философско-социологическими работами Е.В. Де Роберти [Сорокин, 2014, с.291-292]. С учетом признания П.А. Сорокиным ключевых идей своего великого учителя естественно ожидать, что в предметной области социологии философии мы также будем наблюдать определенную преемственность. 
Еще в 1912 г. П.А. Сорокин присоединился к позиции Е.В. Де Роберти, который указывал на пропасть между философией и наукой [Сорокин, 2014, с.291]. Оба исследователя были убеждены в безусловной самостоятельности науки и философии как типов мировоззрения. Соответственно, философия понималась не как наука, а в качестве особого и необходимого модуса мысли. Из этого положения П.А. Сорокин исходил в «Социальной и культурной динамике».

При прочтении работы Е.В. Де Роберти «Прошедшее философии» можно обнаружить ряд представлений, присутствующих и в «Социальной и культурной динамике».

Прежде всего я бы отметил «кружевное» восприятие действительности. Например, Е.В. Де Роберти пишет: «Я остановлюсь лишь на главных точках пересечения многочисленных направлений, по которым двигалось развитие философских систем и которые служили канвой для бесконечно разнообразных узоров, плода богатой фантазии длинного ряда поколений, в погоне за цельным гармоническим пониманием природы» [Роберти, 1887, с.6]. Такой гештальт истории философии существенно отличается от простых линейно-древовидных моделей или гештальта круга на великом круге (спирали) у Гегеля.

Вслед за Э.Б. Тайлором, автором книги «Первобытная культура: исследования развития мифологии, философии, религии, языка, искусства и обычаев» (1871), E.В. Де Роберти признает существование первобытной философии, в частности, в формах антропоморфизма, анимизма, супранатурализма [Роберти, 1887, с.362]. Данная точка зрения, разделявшаяся П.А. Сорокиным, представляет интерес в связи с тем, что в историко-философской науке возникновение философии чаще всего связывается только с классово-антагонистическими формациями, что ставит под сомнение существование философии первобытности и ее универсальность как необходимой формы общественного сознания [Попков, Тюгашев, 2017].

Супранатурализм как убеждение в существовании сверхъестетвенного Е.В. Де Роберти считал не только первобытной философией, но и философией народной массы, т. е. громадного большинства населения [Роберти, 1887, с.344]. Так и П.А. Сорокин считал, что философия существует не только на уровне специализированной, профессиональной деятельности, но и на уровне массового, обыденнопрактического философского сознания - так называемой народной или стихийной философии.

П.А. Сорокин унаследовал от своего наставника идею психофизиологической детерминации конкретных философских учений. Согласно Е.В. Де Роберти, содержание каждой метафизической системы определяется индивидуальными иллюзиями, патологическими влияниями, идиосинкразиями и иными психофизиологическими факторами [Роберти, 1887, с.331-332]. П.А. Сорокин при характеристике философских концепций предлагал учитывать «вертность» психики, тип темперамента.

Е.В. Де Роберти констатировал факт неустранимого философского разнообразия, присутствующего в каждой эпохе развития философской мысли: «Материализм не ра3, в истории философии, господствовал над другими системами и в настоящую эпоху составляет одно из самых распространенных мировоззрений. Но он никогда не был единственным способом объяснения общей совокупности явлений. Рядом 
с ним, иногда решительно заглушая его голос, в великом хоре руководящих идей человечества, постоянно слышались и другие, прямо противоположные мнения» [Роберти, 1887, с.21]. На мой взгляд, учет факта параллелизма развития основных философских направлений [Роберти, 1887, с.37] ориентирует философа не на окончательную и безусловную победу своего направления, поскольку она невозможна, а на тот ментальный опыт, который стал его основой, на его расширение, систематизацию и концептуализацию, включение в кружево разнообразных философских коммуникаций с перспективой собственной социокультурной трансформации.

Напомним, что Е.В. Де Роберти выделял три основных типа метафизики, соотношение которых в исторической динамике описывалось через колебательные движения вокруг центральной оси [Роберти, 1887, с.207-208]. Аналогичным образом П.А. Сорокин описывал динамику основных культурных типов.

Как и П.А. Сорокин, Е.В. Де Роберти выделял смешанные системы философии. По его оценке, они преобладали в «прошедшем» философии [Роберти, 1887, с.207]. Данное преобладание он объяснял логической непоследовательностью большинства философов, а также компромиссами, заключением союзов даже между противоположными философскими школами [Роберти, 1887, с.206].

В работе Е.В. Де Роберти мы находим характерные для «Социальной и культурной динамики» циклично-волновые представления о развитии философии.

Так, он указывал на периодические повторения взглядов в философской эволюции человечества: «История философии изобилует явлениями “повторности”. Мы называем так возвращение на историческую сцену, через более или менее долгие промежутки времени, одних и тех же руководящих мнений, теорий, способов объяснения, наконец, целых законченных мировоззрений. Летописи метафизики переполнены этими воспроизведениями прежних заблуждений, этими возрождениями забытых систем, этими внезапными возвращениями к прошедшему, казавшемуся навсегда похороненным» [Роберти, 1887, с.222]. Данное представление историкофилософского процесса позволяет отнести Е.В. Де Роберти к одному из наиболее ранних предтеч школы русского циклизма.

Представляется любопытным, что Е.В. Де Роберти использует акваморфизмы «волна», «прилив», «отлив», парадигму колебательного процесса, широко представленные в «Социальной и культурной динамике» и в других работах П.А. Сорокина [Тюгашев, 2020]. Так, например, Е.В. Де Роберти писал: «Философская мысль беспокойно металась из одной крайности в другую. Торжество материализма неизменно вело к господству идеалистического направления, а усиление последнего вызывало, как необходимую реакцию, распространение материалистических взглядов. За двумя такими волнами, отделяя их от новой смены материалистического прилива идеалистическим отливом, наступал обыкновенно период господства среднего направления: особым расположением умов начинали пользоваться бесплодные попытки сенсуализма, стремившегося, в свою очередь, положить конец вечным колебаниям философской мысли» [Роберти, 1887, с.427].

Обратим внимание и на сходство стратегий терминообразования. В отношении Е.В. Де Роберти указывается на его «склонность к изобретению и неоправданному использованию новых терминов, таких как “мезологический”, “мезоиспотический”, 
“этелизм”» [Голосенко, 2001, с.106]. Неудачные, отталкивающие читателя термины («идеациональный», «сенсатный») вводил и П.А. Сорокин.

Резюмируя изложенное, можно сделать вывод о том, что П.А. Сорокин в значительной мере разделял взгляды Е.В. Де Роберти на философию и историко-философский процесс. Многие образы, представления и наблюдения, которые мы связываем с «Социальной и культурной динамикой», мы находим в «Прошедшем философии...». Ряд ключевых идей своего учителя П.А. Сорокин обосновал посредством количественного анализа.

\section{Неотрадиционалистская перспектива в социологии философии}

Итак, традиция становления социологии философии является достаточно длительной. Из работ в данной области замечена только «Социология философий» Р. Коллинза. Но, как мы видели, ей предшествовало несколько «кандидатов в парадигму». Но все же не исключено, что именно труд Р. Коллинза уже можно рассматривать в качестве парадигмального исследования.

По крайней мере, оно вдохновило появление серии работ по социологии философии как за рубежом [Fuller, 2002; Kusch, 2005; The sociology..., 2000], так и в России [Красиков, 2014; Семенков, 2011]. Данные работы сфокусированы в основном на конфликтных отношениях внутри философского сообщества.

Наряду с этим поставлена проблема описания позитивных философских коммуникаций как внутри философского сообщества, так и в его отношениях с социумом [Резник, Овчинников, Деменев, Жгилева, Тюгашев, Дрегало, Фомин, Зашихина, Шадрина, Шубина, 2019]. Тем самым в социологию философии реинтегрируется классическое наследие Платона и О. Конта, акцентировавшее внимание на социальной функции и социальной роли философии.

На очереди актуализация и реинтеграция результатов исследований Е.В. Де Роберти и П.А. Сорокина. Необходимо восстановление, возобновление и обновление исследовательской традиции в области социологии философии во всей ее полноте.

\section{Литература}

Бочкарева В.И. Теоретико-методологическая полемика в истории отечественной социологии (Б.А. Кистяковский - П.А. Сорокин) // Наследие. Сыктывкар, 2017, №2 (11). - С.101-110.

Буланова М.Б. Деятельность П.А. Сорокина в Санкт-Петербургском психоневрологическом институте // Наследие. Сыктывкар, 2019а, № 1 (14). - С.9-23.

Буланова М.Б. Социология и социологи на факультете общественных наук Петроградского университета // Наследие. Сыктывкар, 2019б, №2 (15). - С.89-98.

Возчиков Д.В. Философы или жрецы? Брахманы в описании венецианского путешественника Никколо Конти // Розенберговский сборник: востоковедные исследования и материалы / Ред.-сост. Т.В. Ермакова. СПб.: Издательство А. Голода, 2014. - С.347-352.

Голосенко И.А. Евгений Де Роберти: интеллектуальный профиль // Социологические исследования. М., 2001, №2. - С.99-107.

Диоген Лаэртский. О жизни, учениях и изречениях знаменитых философов. М.: Мысль, 1986. - 571 с. Золотарёв В.П. Н.И. Кареев и П.А. Сорокин // Наследие. Сыктывкар, 2013, № 3. - С.78-89.

Золотарев В.П. П.Л. Лавров и П.А. Сорокин // Наследие. Сыктывкар, 2014a, №1 (4). - С.103-108. 
Золотарев В.П. М.М. Ковалевский и П.А. Сорокин // Наследие. Сыктывкар, 2014б, №2 (5). - С.129-139.

Интервью с профессором Рэндаллом Коллинзом // Журнал социологии и социальной антропологии. СПб., 2004, №1. - С.10-26.

История теоретической социологии. Социология XIX века: от появления новой науки до предвестников ее первого кризиса. М.: Академический проект, 2020. - 370 с.

Коллинз Р. Социология философий: глобальная теория интеллектуального изменения. Новосибирск: Сибирский хронограф, 2002. - $1281 \mathrm{c}$.

Комарный В.П. Социологический подход к истории философии (Е.В. Де Роберти) // Известия высших учебных заведений. Поволжский регион. Гуманитарные науки. Философия. Самара, 2013, № 2 (26). - C. $43-48$.

Красиков В.И. Философия: потеря социологической девственности? // Вестник Томского государственного университета. Философия. Социология. Политология. Томск, 2010, №1(9). - С.5-16.

Красиков В.И. Социальные сети русской философии XIX-XX вв. М.: Директ-Медиа, 2014. - 400 с.

Кун Т. Структура научных революций. М.: ООО «Издательство АСТ», 2003. - 605 с.

Некрасов Р.В., Федосов Л.С. Социология архитектуры и пространства в трудах П.А. Сорокина // Питирим Сорокин и парадигмы глобального развития XXI века (к 125-летию со дня рождения) / отв. ред. В.А. Сулимов, Л.В. Гурленова. Сыктывкар: Изд-во СыктГУ, 2014. - С.655-663.

Медушевский Л.Н. Формирование социологической концепции П. Сорокина // Питирим Александрович Сорокин / под ред. В.В. Сапова. М.: Российская политическая энциклопедия (РОССПЭН), 2013. - C.107-118.

Меняева М.П. Характеристика науки как социокультурного феномена в творчестве П.А. Сорокина // Первые Лойфмановские чтения: Аксиология научного познания. Екатеринбург: Изд-во Урал. ун-та, 2006. Вып. 3. - С.41-46.

Муравьев В.В. Философия и социология религии в трудах П.А. Сорокина // Человек. Культура. Образование. Сыктывкар, 2016, № 3 (21). - С.159-172.

Орлова E.B. Закон больших чисел vs закон малых чисел: закономерность vs случайность // Образование. Наука. Карьера /отв. ред А.А. Горохов. Курск: ЗАО «Университетская книга», 2019. Т. 2. - C.139-142.

Попков Ю.В., Тюгашев Е.А. Феномен первобытной философии // Elmi Әsərlər. Баку, 2017, №1 (28). C.85-90.

Попков Ю.В., Тюгашев Е.А. Учение о философских менталитетах П.А. Сорокина // Национальная философия в глобальном мире: материалы Первого белорусского философского конгресса (Республика Беларусь, г. Минск, 18-20 октября 2017 г.). Минск: Право и экономика, 2018. - С.58-64.

Попкова Н.В. Социология философии: трудности развития // Социологические исследования. М., 2019, №8. - C.133-142.

Поппер К.Р. Открытое общество и его враги. Т. 1: Чары Платона. М.: Феникс, Международный фонд «Культурная инициатива», 1992. - 448 с.

Резник Ю.М., Овчинников О.В., Деменев А.Г., Жгилева Л.А., Тюгамев Е.А., Дрегало А.А., Фомин К.В., Зашихина И.М., Шадрина О.Н., Шубина П.В. Философские коммуникации в современной России: круг общения и востребованность философа // Личность. Культура. Общество. М., 2019, №3-4 (103-104). - C.223-235.

Роберти E.[B.] Прошедшее философии. Опыт социологического исследования общих законов развития философской мысли. М.: Типография В.В. Исленьева, 1887. - 658 с.

Розов Н.С. Идеи и интеллектуалы в потоке истории: макросоциология философии, науки и образования. Новосибирск: Манускрипт, 2016. -344 с.

Сапов В.В. Питирим Сорокин и Е.В. Де-Роберти // Наследие. Сыктывкар, 2019, №2 (15). - С.186-190.

Сандстром Г. Питирим Сорокин и эффект Матфея в Мексике: размышления о социологии науки Мертона // Социология науки и технологий. СПб., 2010, №4. - С.139-153.

Семенков В.Е. Философское знание: модусы производства и признания. СПб.: Алетейя, 2011. - 222 с.

Смирнов М.Ю. Концепция религии в социологии П.А. Сорокина // Питирим Александрович Сорокин и современные проблемы социологии: к 120-летию со дня рождения П.А. Сорокина и 20-летию факультета социологии СПбГУ / отв. ред.: А.О. Бороноев, Н.Г. Скворцов. СПб.: Изд-во СанктПетербургского государственного университета, 2009. Т. 2. - С.433-437.

Сорокин П.А. Социальная и культурная динамика. М.: Астрель, 2006. - 1176 с. 
Сорокин П.А. Памяти лидера неопозитивизма Е.В. де-Роберти // Наследие. Сыктывкар, 2019, №2 (15). - С.191-192.

Сорокин П.А. Ранние сочинения: 1910-1914 годы. СПб.: Изд. дом «Міръ», 2014. - 832 с.

Сухая B.B. Факторы социокультурных трансформаций искусства в философии культуры Питирима Сорокина. М.: Оргсервис-2000, 2011. - 156 с.

Тюгашев Е.А. Метафилософия Питирима Сорокина // Наследие. Сыктывкар, 2015, №2 (7). - С.97-106.

Tюгашев E.A. Акватическая картина мира в социокультурной феноменологии П.А. Сорокина // Наследие. Сыктывкар, 2020, № 1(16). - С.45-60.

Тюгашев Е.А., Попков Ю.В. П.А. Сорокин о менталитете // Наследие. 2018, №1 (12). - С.16-27.

Тюгашев И.Е. Питирим Сорокин о первобытном искусстве // Питирим Сорокин и парадигмы глобального развития XXI века (к 130-летию со дня рождения) / гл. ред. О.А. Сотникова. Сыктывкар: Издво СГУ им. Питирима Сорокина, 2019. - С.258-262.

Фуллер C. Социология интеллектуальной жизни: карьера ума внутри и вне академии. М.: Издательский дом «Дело» РАНХиГС, 2018. - 384 с.

Хренов Н.А. Между линейным и циклическим принципом: история искусства в ракурсе социодинамики П. Сорокина // Культура и искусство. М., 2014а, №4. - С.381-392.

Хренов Н.А. Между линейным и циклическим принципом: история искусства в ракурсе социодинамики П. Сорокина. Статья вторая // Культура и искусство. М., 2014б, №5. - С.561-576.

Яблоков И.Н. Проблемы религии в социологии и философии Питирима Сорокина // Вопросы философии. М., 2019, №3. - С. 69-76.

Collins $R$. The Sociology of Philosophies: A Global Theory of Intellectual Change. Cambridge: Harvard University Press, 1998. - 1120 p.

De Roberty E.[V.] Lancienne et la nouvelle philosophie: essai sur les lois générales du développement de la philosophie. Paris: F. Alcan, 1887. - 364 p.

Fuller S. Prolegomena to a Sociology of Philosophy in the Twentieth-Century English-Speaking World // Philosophy of the Social Sciences, 2002, No. 2. - Pp.151-177.

Kusch M. Psychologism. A case study in the sociology of philosophical knowledge. London: Routledge, 2005. $-326 \mathrm{p}$.

Sorokin P. Social and Cultural Dynamics: A Study of Change in Major Systems of Art, Truth, Ethics, Law and Social Relationships. Boston P. Sargent, 1957. - 718 p.

The sociology of philosophical knowledge Ed. by M. Kusch London: Springer Science \& Business Media, 2000. -218 p.

Tversky A., Kahneman D. Belief in the law of small numbers // Psychological Bulletin, 1971, No. 2. Pp. 105-110.

\section{References}

Bochkareva V.I. Teoretiko-metodologicheskaja polemika v istorii otechestvennoj sociologii (B.A. Kistjakovskij - P.A. Sorokin) [Theoretical and methodological polemics on the history of the Russian sociology (B.A. Kistyakovskii - P.A. Sorokin)] // Nasledie [Heritage]. Syktyvkar, 2017, No 2 (11). - pp.101-110.

Bulanova M.B. Dejatelnost P.A. Sorokina $v$ Sankt-Peterburgskom psihonevrologicheskom institute [Sorokin's activities in the St. Petersburg Psycho-neurological Institute] // Nasledie [Heritage]. Syktyvkar, 2019a, No 1 (14). - pp.9-23.

Bulanova M.B. Sociologija i sociologi na fakultete obshhestvennyh nauk Petrogradskogo universiteta [Sociology and sociologists at the faculty of social sciences of the Petrograd university] // Nasledie [Heritage]. Syktyvkar, 2019b, No 2 (15). - pp.89-98.

Vozchikov D.V. Filosofy ili zhrecy? Brahmany v opisanii venecianskogo puteshestvennika Nikkolo Konti [Philosophers or Priests? The Brahmins in Niccolo Conti's Description] // Rozenbergovskij sbornik: vostokovednye issledovanija i materialy [Rosenberg collection: Oriental studies and materials]. Ed. by T.V. Ermakova. Saint Petersburg, Izdatelstvo A. Goloda, 2014. - pp.347-352.

Golosenko I.A. Evgenij de Roberti: intellektualnyj profil [Eugene de Roberti: intellectual profile] // Sociologicheskie issledovanija [Sociological Research]. Moscow, 2001, No 2. - pp.99-107.

Diogen Lajertskij. O zhizni, uchenijah i izrechenijah znamenityh filosofov [On the lives, doctrines and sayings of famous philosophers]. Moscow, Mys1, 1986. - 571 p. 
Zolotarjov V.P. N.I. Kareev i P.A. Sorokin [N.I. Kareev and P.A. Sorokin] // Nasledie. [Heritage]. Syktyvkar, 2013, No 3. - pp.78-89.

Zolotarev V.P. P.L. Lavrov i P.A. Sorokin [P.L. Lavrov and P.A. Sorokin] // Nasledie [Heritage]. Syktyvkar, 2014, No 1 (4). - pp.103-108.

Zolotarev V.P. M.M. Kovalevskij i P.A. Sorokin [M. M. Kowalewski and P. A. Sorokin] // Nasledie [Heritage]. Syktyvkar, 2014, No 2 (5). - pp.129-139.

Intervju s professorom Rjendallom Kollinzom [Interview with professor Randall Collins] // Zhurnal sociologii $i$ socialnoj antropologii [The Journal of Sociology and Social Anthropology]. Saint Petersburg, 2004, No 1. - Pp.10-26.

Istorija teoreticheskoj sociologii. Sociologija XIX veka: ot pojavlenija novoj nauki do predvestnikovee pervogo krizisa [History of theoretical sociology. Sociology of the nineteenth century: from the emergence of a new science to the harbingers of its first crisis.]. Moscow, Akademicheskij proekt, 2020. $-370 \mathrm{p}$.

Kollinz R. Sociologija filosofij: globalnaja teorija intellektualnogo izmenenija [The Sociology of Philosophies: A Global Theory of Intellectual Change]. Novosibirsk, Sibirskij hronograf, 2002. - 1281 p.

Kosharnyj V.P. Sociologicheskij podhod $k$ istorii filosofii (E.V. de Roberti) [Sociological approach to the history of philosophy (E. V. de Roberti) University proceedings] // Izvestija vysshih uchebnyh zavedenij. Povolzhskij region. Gumanitarnye nauki. Filosofija [Volga region. Humanities. Philosophy]. Samara, 2013, No 2 (26). - pp.43-48.

Krasikov V.I. Filosofija: poterja sociologicheskoj devstvennosti? [Philosophy: loss of sociological virginity?] // Vestnik Tomskogo gosudarstvennogo universiteta. Filosofija. Sociologija. Politologija [Tomsk State University Journal. Philosophy. Sociology. Political science]. Tomsk, 2010, No 1(9). - pp.5-16.

Krasikov V.I. Socialnye seti russkoj filosofii XIX-XX vv [Social networks of Russian philosophy of the XIXXX centuries.]. Moscow, Direkt-Media, 2014. -400 p.

Kun T. Struktura nauchnyh revoljucij [The Structure of Scientific Revolutions]. Moscow, OOO «Izdatelstvo $\mathrm{ACT} \gg, 2003 .-605 \mathrm{p}$.

Nekrasov R.V., Fedosov L.S. Sociologija arhitektury i prostranstva v trudah P.A. Sorokina [Sociology of architecture and space in the works of P.A. Sorokin] // Pitirim Sorokin i paradigmy globalnogo razvitija XXI veka (k 125-letiju so dnja rozhdenija) [Pitirim Sorokin and paradigms of global development of the XXI century (to the 125th anniversary of his birth)] / Ed. by V.A. Sulimov \& L.V. Gurlenova. Syktyvkar, Izd-vo SyktGU, 2014. - pp.655-663.

Medushevskij L.N. Formirovanie sociologicheskoj koncepcii P. Sorokina [The formation of the sociological concept of P. Sorokin] // Pitirim Aleksandrovich Sorokin [Pitirim Alexandrovich Sorokin] / Ed. by V.V. Sapov. Moscow, Rossijskaja politicheskaja jen-ciklopedija (ROSSPEN), 2013. - pp.107-118.

Menjaeva M.P. Harakteristika nauki kak sociokulturnogo fenomena v tvorchestve P.A. Sorokina [Characteristics of science as a sociocultural phenomenon in the works of P. A. Sorokin] // Pervye Lojfmanovskie chtenija: Aksiologija nauchnogo poznanija [First Loifman'readings: Axiology of scientific knowledge]. Ekaterinburg, Izd-vo Ural. un-ta, 2006. Iss. 3. - pp.41-46.

Muravev V.V. Filosofija i sociologija religii v trudah P.A. Sorokina [Philosophy and sociology of religion in the works of P.A. Sorokin] // Chelovek. Kultura. Obrazovanie [Human. Culture. Education]. Syktyvkar, 2016, No 3 (21). - pp.159-172.

Orlova E.V. Zakon bolshih chisel vs zakon malyh chisel: zakonomernost vs sluchajnost [Law of large numbers vs law of small numbers: regularity vs randomness] // Obrazovanie. Nauka. Karera [Education. Science. Career]. Ed. by A.A. Gorohov. Kursk, ZAO «Universitetskaja kniga», 2019. Vol. 2. - pp.139-142.

Popkov Ju.V., Tyugashev E.A. Fenomen pervobytnoj filosofii [The phenomenon of primitive philosophy] // Elmi Zsarlar [Scientific Works]. Baku, 2017, No 1 (28). - pp.85-90.

Popkov Ju.V., Tyugashev E.A. Uchenie o filosofskih mentalitetah P. A. Sorokina [The doctrine of philosophical mentalities by P. A. Sorokin] // Nacionalnaja filosofija v globalnom mire: materialy Pervogo belorusskogo filosofskogo kongressa (Respublika Belarus, g. Minsk, 18-20 oktjabrja 2017 g.) [ National philosophy in the global world: materials of the First Belarusian philosophical Congress (Republic of Belarus, Minsk, October 18-20, 2017)]. Minsk, Pravo i jekonomika, 2018. - pp.58-64.

Popkova N.V. Sociologija filosofii: trudnosti razvitija [Sociology of philosophy: development difficulties] // Sociologicheskie issledovanija [Sociological Research]. Moscow, No 8, 2019. - pp.133-142.

Popper K.R. Otkrytoe obshhestvo i ego vragi. T. 1: Chary Platona [The Open Society and Its Enemies. Vol. 1. The Spell of Plato]. Moscow, Feniks, Mezhdunarodnyj fond «Kulturnaja iniciativa», 1992. - 448 p.

Reznik Ju.M., Ovchinnikov O.V., Demenev A.G., Zhgileva L.A., Tyugashev E.A., Dregalo A.A., Fomin K.V., Zashihina I.M., Shadrina O.N., Shubina P.V. Filosofskie kommunikacii v sovremennoj Rossii: krug 
obshhenija $i$ vostrebovannost filosofa [Philosophical communications in modern Russia: the circle of communication and the demand for a philosopher] // Lichnost. Kultura. Obshhestvo [Person. Culture. Society]. Moscow, 2019, No 3-4 (103-104). - pp.223-235.

Roberti E.[V.] Proshedshee filosofii. Opyt sociologicheskogo issledovanija obshhih zakonov razvitija filosofskoj mysli [Philosophical past. Experience of sociological research of general laws of philosophical thought development]. Moscow, Tipografija V.V. Isleneva, 1887. - 658 p.

Rozov N.S. Idei i intellektualy v potoke istorii: makrosociologija filosofii, nauki i obrazovanija [Ideas and intellectuals in the flow of history: macrosociology of philosophy, science and education]. Novosibirsk, Manuskript, 2016. - 344 p.

Sapov V.V. Pitirim Sorokin i E.V. de Roberti [Pitirim Sorokin and E.V. De Roberti] // Nasledie [Heritage]. Syktyvkar, 2019, No 2 (15). - pp.186-190.

Sandstrom G. Pitirim Sorokin i jeffekt Matfeja v Meksike: razmyshlenija o sociologii nauki Mertona [Pitirim Sorokin And The Matthew Effect In Mexico: A Reflection On Merton's Sociology Of Science] // Sociologija nauki i tehnologij [Sociology of Science and Technology]. Saint Petersburg, 2010, No 4. - Pp.139-153.

Semenkov V.E. Filosofskoe znanie: modusy proizvodstva i priznanija [Philosophical knowledge: modes of production and recognition]. Saint Petersburg, Aletejja, 2011. - 222 p.

Smirnov M.Ju. Koncepcija religii v sociologii P.A. Sorokina [The concept of religion in the sociology of P.A. Sorokin] // Pitirim Aleksandrovich Sorokin i sovremennye problemy sociologii: $k$ 120-letiju so dnja rozhdenija P.A. Sorokina i 20-letiju fakulteta sociologii SPbGU [Pitirim A. Sorokin and modern problems of sociology: to the 120th anniversary of the birth of P. A. Sorokin and the 20th anniversary of the faculty of sociology of St. Petersburg state University] / Ed. by A.O. Boronoev \& N.G. Skvorcov. Saint Petersburg, Izd-vo Sankt-Peterburgskogo gosudarstvennogo universiteta, 2009. Vol. 2. - pp.433-437.

Sorokin P.A. Social'naya i kul turnaya dinamika [Social and cultural dynamics]. M.: Astrel, 2006. - 1176 p.

Sorokin P.A. Pamjati lidera neopozitivizma E.V. de Roberti [Neopositivism leader E.V. De-Roberti: in Memoria] // Nasledie [Heritage]. Syktyvkar, 2019, No 2 (15). - pp.191-192.

Sorokin P.A. Rannie sochinenija: 1910-1914 gody [Early writings: 1910-1914]. Saint Petersburg, Izd. dom «Mir», 2014. - $832 \mathrm{p}$.

Suhaja V.V. Faktory sociokulturnyh transformacij iskusstva v filosofii kultury Pitirima Sorokina [Factors of socio-cultural transformations of art in Pitirim Sorokin's philosophy of culture]. Moscow, Orgservis-2000, 2011. $-156 \mathrm{p}$.

Tyugashev E.A. Metafilosofija Pitirima Sorokina [Metaphilosophy of Pitirim Sorokin] // Nasledie [Heritage]. Syktyvkar, 2015, No 2 (7). - pp.97-106.

Tyugashev E.A. Akvaticheskaja kartina mira v sociokulturnoj fenomenologii P.A. Sorokina [Aquatic world view in the sociocultural phenomenology of Pitirim Sorokin] // Nasledie [Heritage]. Syktyvkar, 2020, No 1(16). - pp.45-60.

Tyugashev E.A., Popkov Ju.V. P.A. Sorokin o mentalitete [Sorokin on mentality] // Nasledie [Heritage]. Syktyvkar, 2018, No 1 (12). - pp.16-27.

Tyugashev I.E. Pitirim Sorokin o pervobytnom iskusstve [Pitirim Sorokin on primitive art] // Pitirim Sorokin i paradigmy globalnogo razvitija XXI veka (k 130-letiju so dnja rozhdenija) [Pitirim Sorokin and paradigms of global development of the XXI century (to the 130th anniversary of his birth)] / Ed. by O.A. Sotnikova. Syktyvkar, Izd-vo SGU im. Pitirima Sorokina, 2019. - pp.258-262.

Fuller S. Sociologija intellektualnoj zhizni: karera uma vnutri $i$ vne akademii [The Sociology of Intellectual Life: The Career of the Mind in and Around Academy]. Moscow, Izdatelskij dom «Delo» RANHiGS, 2018. -384 p.

Hrenov N.A. Mezhdu linejnym i ciklicheskim principom: istorija iskusstva v rakurse sociodinamiki P. Sorokina [Between the linear and cyclical principle: the history of art in the perspective of sociodynamics P. Sorokin] // Kultura i iskusstvo [Culture and art]. Moscow, 2014a, No 4. - pp.381-392.

Hrenov N.A. Mezhdu linejnym $i$ ciklicheskim principom: istorija iskusstva $v$ rakurse sociodinamiki P. Sorokina. Statja vtoraja [Between the linear and cyclical principle: the history of art in the perspective of sociodynamics P. Sorokin. Article two] // Kultura i iskusstvo [Culture and art]. Moscow, 2014b, No 5. - pp.561-576.

Jablokov I.N. Problemy religii v sociologii i filosofii Pitirima Sorokina [Problems of religion in the sociology and philosophy of Pitirim Sorokin] // Voprosy filosofii [Problems of philosophy]. Moscow, 2019, No 3. pp. 69-76. 